\title{
INTERthesis
}

\section{MULHERES E LUTAS POLÍTICAS: CONQUISTAS E LIMITES VIVIDOS NA SEGUNDA METADE DO SÉCULO XX}

\section{Resumo:}

Flávia Fernandes de Carvalhaes ${ }^{1}$ Sonia Regina Vargas Mansano ${ }^{2}$

A segunda metade do século $X X$ foi um período marcado por conquistas e retrocessos importantes no campo das lutas pelos direitos femininos. $O$ presente estudo mapeou e descreveu parte dos discursos, imagens e movimentos empreendidos naquele período histórico bem como seus efeitos sobre a vida da população. Adotando uma perspectiva de análise histórica e teórica, a descrição debruçou-se, primeiramente, sobre as lutas realizadas em alguns países da Europa e nos Estados Unidos, evidenciando seus principais desafios e dificuldades. Em seguida, mapearam-se as lutas empreendidas no Brasil, tendo como eixo de análise o enfrentamento das desigualdades. Ao final, considera-se que as lutas políticas realizadas no período analisado tiveram como maior mérito o rompimento e a exploração das fronteiras de gênero.

Palavras-chave: Mulheres. Política. Resistência.

\section{INTRODUÇÃO}

A segunda metade do século $X X$ foi marcada pela expansão de direitos femininos que ajudaram a desenhar significativas mudanças nas condições de vida de mulheres e homens em países ocidentais, destacando-se o direito ao trabalho, educação e saúde (DUBY; PERROT, 1991). Apesar dos avanços, alguns discursos e práticas pautados em modelos tradicionais de feminilidade e masculinidade persistem, marcam os corpos e produzem efeitos na construção dos modos de viver e se relacionar (DUBY; PERROT, 1991). Tais diferenças já se faziam presentes em décadas passadas, principalmente no que se refere às demandas díspares colocadas para as mulheres que deveriam ser ora delicadas e maternais, ora lutadoras e ativas, ora ainda intelectuais e profissionais, a depender do contexto em

\footnotetext{
1 Doutora em Psicologia pela Universidade Federal de Santa Catarina, Florianópolis, SC, Brasil. Professora da Universidade Norte do Paraná e Universidade Estadual de Londrina. Psicóloga na política de Socioeducação da cidade de Londrina junto à política de Assistência Social, Londrina, PR, Brasil E-mail: carvalhaes1@yahoo.com.br

2 Doutora em Psicologia pela Pontifícia Universidade Católica de São Paulo, pós-doutorado na mesma universidade, São Paulo, São Paulo, SP, Brasil. Professora da Universidade Estadual de Londrina, Londrina, PR, Brasil E-mail: smansano@sercomtel.com.br
}

R. Inter. Interdisc. INTERthesis, Florianópolis, v.13, n.2, p. 141-164 Mai-Ago. 2016 
que se encontravam. Isso se torna mais evidente quando analisamos a disseminação de discursos e imagens, na acepção foucaultiana de dizibilidades e visibilidades produzidas socialmente (FOUCAULT, 2000), lançados sob inspiração do discurso feminista, como é o caso das propagandas de soutiens que, no final da década de 1960, sugeriam a libertação das mulheres do domínio masculino, ao mesmo tempo em que circulavam discursos e imagens que mostravam as mulheres como sendo as únicas capazes de realizar o trabalho doméstico e educativo, com rendimento e qualidade satisfatórios (CARVALHAES, 2015).

Analisar as lutas políticas do século $X X$ implica percorrer algumas forças que ajudaram a tecer novas possibilidades de existência para homens e mulheres em um momento que foi marcado por rupturas e desafios na construção dos valores e dos modos de viver em sociedade. Adotando essa perspectiva de produção social, Foucault assinala:

O sujeito se constitui através das práticas de sujeição ou, de maneira mais autônoma, através de práticas de liberação, de liberdade (...) a partir, obviamente, de um certo número de regras, de estilos, de conversações que podemos encontrar no meio cultural (FOUCAULT, 2011, p. 291)

A produção de sujeições e liberdades implicaram enfrentamentos diversos, em especial quando analisamos em termos de resistências. Estas, de acordo com Michel Foucault, podem ser compreendidas como pontos "móveis e transitórios, que introduzem na sociedade clivagens que se deslocam, rompem unidades e suscitam reagrupamentos, percorrem os próprios indivíduos, recortando-os e os remodelando, traçando neles, em seus próprios corpos e almas, regiões irredutíveis" (FOUCAULT, 1988, p. 92). Sempre no plural, os focos de resistência presentes nas lutas políticas das mulheres foram inscritos num campo de forças complexo, onde se afirmavam desde modelos mais tradicionais de gênero até as ações de rupturas. Pode-se dizer, então, que foi em meio a condições adversas de existência, que os exercícios de resistência tornaram-se possíveis; afinal, "se há relações de poder em todo o campo social, é porque há liberdade por todo lado" (FOUCAULT, 2011, p. 277).

Foi exatamente analisando este campo de forças em conflito, com a pluralidade de resistências que ganharam marcas "possíveis, necessárias, improváveis, espontâneas, selvagens, solitárias, planejadas, arrastadas, violentas, irreconciliáveis" (FOUCAULT, 1988, p.106), que este ensaio ganhou contornos. Seu objetivo consiste em percorrer parte dessas lutas, buscando compreender como 
ações situadas expandiram-se e ganharam dimensões políticas, inclusive com força de lei, para que homens e mulheres passassem a compartilhar direitos e deveres. Percorrendo a emergência histórica de parte dessas lutas procuraremos, conforme dito por Foucault, compreender "o esquema das modificações que as correlações de forças implicam através de seu próprio jogo" (FOUCAULT, 1988, p. 94), atentando para as rupturas e desvios que elas precipitaram e que foram amplamente analisadas por Lagrave (1991).

Assim, o presente ensaio foi dividido em duas partes: primeiramente, são analisadas algumas lutas que se ensaiaram em países da Europa e nos Estados Unidos e impactaram sobremaneira a vida daquelas populações. $O$ texto segue com um mapeamento dos efeitos dessas lutas no Brasil, entre as décadas de $1960 \mathrm{e}$ 1990, com destaque à análise das conquistas das mulheres no âmbito público, sobretudo na ocupação de espaços que outrora eram demarcados como masculinos.

\section{LUTAS SOCIAIS NA EUROPA E ESTADOS UNIDOS}

Os avanços tecnológicos consolidados durante as guerras mundiais implicaram o aperfeiçoamento e maior acessibilidade a produtos e serviços, que incluíam água quente, instalações sanitárias, telefone, máquina de lavar roupa, aspirador de pó, entre outros aparatos tecnológicos (LEFAUCHEUR, 1991). O acesso a esses equipamentos imprimiu um novo regime de trabalho doméstico para muitas mulheres. A apropriação dos espaços sociais, como, por exemplo, aqueles ligados à vida social e profissional resultou, por um lado, em avanços na luta por direitos, que davam destaque ao princípio da igualdade jurídica entre homens e mulheres. Por outro lado, tais equipamentos aumentaram o tempo livre que passou a ser dirigido às jornadas de trabalho fora do âmbito familiar, não se convertendo necessariamente em tempo de lazer ou exercício de outras comodidades. Diante dessas transformações, três dimensões são fundamentais para essa análise, a saber: a relevância social dos movimentos feministas nas lutas políticas, a participação dos meios de comunicação na ordem normativa e outras lutas políticas empreendidas pelo pós-feminismo.

R. Inter. Interdisc. INTERthesis, Florianópolis, v.13, n.2, p. 141-164 Mai-Ago. 2016 


\subsection{A RELEVÂNCIA SOCIAL DOS MOVIMENTOS FEMINISTAS NAS LUTAS POLITICAS}

Após a queda dos regimes autoritários na Europa, emergiram diversas reivindicações pelas quais as mulheres foram legal e socialmente reconhecidas como cidadãs plenas. Os efeitos disso podem ser notados no texto da Declaração Universal dos Direitos Humanos, promulgado em 1948, assim como em constituições complementares e leis instituídas em diversos países ocidentais, que colocavam a igualdade de direitos entre homens e mulheres como uma das prioridades a serem efetivadas. Apesar disso, até meados da década de 60, os sistemas jurídicos eram subsidiados por racionalidades oscilatórias inspiradas ora em ideais emancipatórios, ora em noções tradicionais de deveres e direitos entre marido e mulher no âmbito conjugal (SINEAU, 1991).

Segundo Thébaud (1991), foi apenas em meados da década de 1960 que a maior parte dos países ocidentais começou a envolver-se na luta por mudanças nas maneiras de conceber e experimentar a relação entre homens e mulheres. Os avanços tecnológicos (como a invenção de Gregory Pinkus da pílula anticoncepcional), os acontecimentos de maio de 68 , os movimentos organizados de mulheres ativistas, entre outros exemplos, criaram condições históricas e políticas propiciadoras de mudanças e inversões nas correlações das forças que distribuíam os gêneros no campo social. Tanto que nos debates feministas, o surgimento da pílula anticoncepcional foi anunciado como um momento de grande ruptura na história das mulheres, pois possibilitou o gerenciamento ativo sobre o próprio corpo (THÉBAUD, 1991).

A partir daquele momento, o número de casamentos decaiu, concomitantemente ao aumento do número de divórcios e da evidência de uma quantidade considerável de crianças educadas em organizações familiares monoparentais, o que desestabilizou parcialmente o ideal de "família nuclear". As diferentes expressões de feminilidade e masculinidade e as novas relações de conjugalidade que se teciam naquele momento, aliadas às reivindicações de grupos de mulheres por maior independência em relação à família, ao trabalho e aos estudos, contribuíram para fortalecer as lutas por igualdade de direitos entre os sexos (SANTANA, 2009).

R. Inter. Interdisc. INTERthesis, Florianópolis, v.13, n.2, p. 141-164 Mai-Ago. 2016 
No que se refere ao trabalho feminino, no entanto, este se tornava comumente aceito e valorizado desde que as mulheres restringissem suas atividades às atribuições tidas como femininas e não interferissem nos postos ocupados pelos homens (LAGRAVE, 1991). As mulheres ocuparam principalmente as vagas do setor terciário, sendo dificultada a sua entrada em profissões tidas como caracteristicamente masculinas, as quais demandavam ações diretivas e executivas. Elas eram também remuneradas de modo desigual em comparação aos homens, o que aponta para conquistas relativas de direitos femininos no campo do trabalho (LAGRAVE, 1991). A divisão sexual do trabalho operava, portanto, uma série de desigualdades que se materializam em estruturas hierárquicas, regimes precários de contratação e assimetrias nas remunerações, o que instigou parte das mulheres a se organizar politicamente na luta por direitos trabalhistas.

Muitas delas procuraram elevar seu nível educacional, apresentando-se as escolas e universidades como contextos que podem subverter parcialmente determinados "destinos" prescritos às mulheres, implicando em mais uma reversão no jogo de poderes. As instituições de ensino, contudo, eram majoritariamente conservadoras, reproduzindo modos de naturalizar e classificar as diferenças entre homens e mulheres ao definir, por exemplo, os prováveis caminhos profissionais de cada sexo. Essa tendência conservadora, entretanto, não foi suficiente para brecar a expansão feminina (FERNANDES; VASCONCELOS, 2010).

\subsection{OS MEIOS DE COMUNICAÇÃO E A ORDEM NORMATIVA}

Seguindo as lutas que marcaram a segunda metade do século $\mathrm{XX}$, destacamse também os modos como tais mulheres foram retratadas nos meios de comunicação, como os jornais, programas televisivos e revistas, cuja circulação é frequente e de fácil acesso. Nesse período, a abrangência da mídia se intensificou, sobretudo devido ao surgimento e maior acessibilidade da televisão e da internet. As maneiras como as informações e imagens eram apresentadas nesses aparatos tecnológicos refletiam as ambivalências da época, "quer como lugar de afirmação de valores definidos como puramente femininos [e masculinos], entre os quais a individualidade, o bem-estar, o amor, a felicidade, quer como amplificador de imagens de mulheres sedutoras" (PASSERINI, 1991, p. 382).

R. Inter. Interdisc. INTERthesis, Florianópolis, v.13, n.2, p. 141-164 Mai-Ago. 2016 
Marcados por discursos e práticas com vieses libertadores, os meios de comunicação apresentavam imagens de mulheres independentes e seguras. Em contrapartida, eram disseminadas também imagens e notícias tradicionais de feminilidade, pautadas no estereótipo da mulher/mãe/dona de casa, zelosa e cuidadora. Os ora evidentes, ora sutis sistemas de opressão e violência que circunscreviam as trajetórias das mulheres em modelos inteligíveis de gênero, aliados à sua expansão econômica e integração na educação e força de trabalho, impulsionaram a articulação de um novo movimento reivindicativo protagonizado por mulheres nas décadas de sessenta e, principalmente, setenta (MARINI, 1991). As feministas, iniciadoras do movimento, problematizaram as dimensões políticas, econômicas e sociais que operavam nos processos de construção de perspectivas normativas de gênero, procurando elaborar ferramentas teóricas para explicar as desigualdades entre homens e mulheres e trabalhando na construção de um sujeito político coletivo: as mulheres (PISCITELLI, 2002).

A fundação, em 1966, da Organização Nacional em Prol das Mulheres foi um dos marcos iniciais da consolidação do movimento feminista estadunidense; sendo que, em 1968, manifestações de mulheres nos Estados Unidos exemplificam a dimensão crítica em que se tecia o movimento, como a expressão de ativistas que teatralizaram no Cemitério Nacional de Arlington o "enterro da feminilidade tradicional", outras que coroaram um carneiro como "Miss América" e ainda um grupo de mulheres que jogaram soutiens, cintas e sombrancelhas postiças numa cesta de lixo chamada "liberdade" (ERGAS, 1991).

Segundo Marini (1991), o movimento feminista organizou-se, primeiramente, por meio das reivindicações de mulheres consideradas privilegiadas (estudantes, artistas, intelectuais) e foi fortemente fundamentado nas leituras de pesquisadoras estadunidenses e europeias. Pela primeira vez na história, o movimento social das mulheres tomou uma amplitude social e política que se materializou na distribuição de escritos feministas publicados em pesquisas, panfletos, jornais, desenhos, grafítis, canções, vídeos e manifestações sociais.

Após 1975 ter sido proclamado pela Organização das Nações Unidas (ONU) como Ano Internacional das Mulheres, assistiu-se ao surgimento de diversas tomadas de posições governamentais, nacionais e internacionais, em favor da igualdade de oportunidades entre homens e mulheres, por meio da promulgação de 
declarações, relatórios e leis (LAGRAVE, 1991). Atenta aos impactos dos ativismos feministas na organização social de países desenvolvidos e de terceiro mundo, a ONU declarou os anos de 1975 a 1985 como a "década da mulher", o que viabilizou a organização de conferências nas cidades de México, Compenhagem e Nairobi (ERGAS, 1991, p. 584). Esses eventos sublinharam a visibilidade pública alcançada por uma sólida rede de mulheres ativistas e contribuíram para que as Nações Unidas adotassem uma série de iniciativas e resoluções em prol das mulheres. A posição da ONU em relação às lutas femininas produziu efeitos políticos na Europa e nos Estados Unidos que reverberaram também no Brasil, como veremos posteriormente.

$\mathrm{Na}$ década de 1980, em consequência principalmente dos efeitos das articulações feministas dos anos de 1970, surgiu nos meios de comunicação de massa a figura da superwomen (THÉBAUD, 1991), que era capaz de equilibrar com sucesso o trabalho, os relacionamentos conjugais e a família. Esta figura materializou as exigências que coexistiam naquele momento histórico, pois a superwomen, apesar de ser apresentada como emblema da mulher emancipada, era sutilmente compreendida como a única responsável pela manutenção do equilíbrio do lar e educação dos filhos. Nota-se, nesse ponto, o quanto as lutas são reversíveis e complexas: e luta pela emancipação no trabalho mantém-se na vizinhança do aceite da dupla jornada de trabalho, fato que colaborou, em alguma medida, para inscrever as mulheres na lógica capitalista de produção acelerada e de totalização da vida no trabalho.

Por tratar-se de um movimento emergente e marcado pela complexidade de opiniões, ainda na década de 1980 o feminismo ganhou o rótulo de "fora da moda" por suas precursoras. A profunda indiferença em dar continuidade à divulgação de diversas lutas empreendidas em décadas passadas foi retratada por jornalistas ocidentais (ERGAS, 1991, p. 587). Contudo, embora este descaso das jovens tenha sido apresentado como um momento de passividade e declínio do movimento feminista, o seu aparente enfraquecimento como movimento social organizado não resultou no seu desaparecimento, mas sim em novas maneiras de articulação política e teórica e na mobilização por novos objetivos e debates, denominados "pósfeminismo" (PRECIADO, 2011). 


\subsection{OUTRAS LUTAS PÓS-FEMINISTAS}

Principalmente na década de 1990, as denominadas pós-feministas se organizaram em torno da crítica à noção de "identidade feminina", frequentemente associada às imagens de fragilidade e sujeição, buscando desconstruir perspectivas identitárias binárias e universalizantes, organizadas em torno do pressuposto da diferença sexual entre homem e da mulher (CARRILLO, 2010). Para essas ativistas, ainda que a afirmação de uma natureza feminina (cristalizada em papéis sociais fixos) se apresentasse como uma estratégia de luta por direitos, essa maneira de conduzir o movimento implicava na afirmação de modelos prescritivos que operavam na reprodução de matrizes delimitadoras e aprisionadoras dos gêneros (BUTLER, 2003).

Segundo Butler (1998) e Haraway (1995), a problematização de perspectivas essencializantes, promulgadas por uma política representacional, possibilitava a visibilidade de outras experiências de vida e configurações de gênero. Uma crítica central ao feminismo vigente era o fato de este considerar a categoria "mulher" sob uma perspectiva hegemônica e homogeneizante, em detrimento das múltiplas experiências étnicas, raciais, de classe e gênero, que posicionam as mulheres de diferentes maneiras nas lutas sociais. Considerava-se, portanto, que os modos heterogêneos como as mulheres se constituíam foi negado em nome de uma suposta identidade feminina universal.

Nesse sentido, Butler (1998) assinalou que a luta pela emancipação de um sujeito feminino universal foi marcada por processos ambíguos, visto reproduzir modelos de dominação combatidos pelo próprio feminismo. Para a autora, a utilização de qualquer categoria identitária nunca se restringe a um efeito descritivo (representativo), pois este implicaria na regulação de padrões de gênero. Assim, a autora (BUTLER, 2001) analisou o viés etnocêntrico e normativo de determinadas categorias que fundamentaram as lutas feministas das décadas de 1960 e 1970 e, em contraposição a noções identitárias, sublinhou as maneiras complexas e localizadas como as perspectivas de gênero se compõem e se expressam.

A circulação de enunciados pós-feministas implicou em rupturas parciais no que vinha se construindo como diretriz dos diferentes movimentos feministas. Desde então, outros focos de pesquisas e lutas ganharam gradativamente espaço nos 
debates acadêmicos e/ou ativistas como, por exemplo, os estudos queer (que problematizam a produção de gênero adotando uma perspectiva da diferença) e os estudos sobre masculinidades (PRECIADO, 2011). Os pressupostos do pósfeminismo colocaram em cena jogos complexos de força que questionavam criticamente a vida regrada de homens e mulheres de maneira a evidenciar variações e transitoriedades. Assim, mesmo que a "opressão sexista seja uma experiência comum a todas as mulheres, não é suficiente para homogeneizar esta experiência" (OLIVEIRA, 2010, p. 29). Ao problematizar apenas os efeitos dos discursos e práticas dominantes nas trajetórias de vida de mulheres brancas, ocidentais e do primeiro mundo, as feministas também reproduziram sistemas colonizadores de opressão e racismo, ao considerar os modos de vida de mulheres negras, lésbicas, orientais, de países de terceiros mundo como abjetas e/ou inexistentes.

Essas críticas foram fundamentais para esclarecer a importância das propostas de interseccionalidade nas pesquisas e ativismos feministas, porquanto estas problematizavam o intercruzamento das dimensões transversais de raça, classe, geração e gênero nos processos de subjetivação, assim como afirma Preciado:

[...] o termo pós-feminismo indica um giro conceitual de debates sobre igualdade e diferença, justiça e reconhecimento, e também do essencialismo e do construtivismo, em direção a debates em torno da produção transversal das diferenças. Marca um deslocamento daquelas posições que partem de uma noção única de diferença sexual e de gênero seja esta entendida em termos essencialistas, em termos marxistas (a divisão sexual do trabalho) ou em termos linguísticos (ordem simbólico ou pré-simbólico)- em direção a uma análise de natureza transversal (PRECIADO apud CARRILLO, 2010, p. 48).

Os saberes interseccionais possibilitaram a apreensão do fato de que pessoas e grupos apresentam diferentes posições na sociedade; por exemplo, um homem de classe popular encontra-se, em determinados contextos, mais vulnerável que uma mulher de classe média.

Em consonância com as propostas de interseccionalidade, Rich (2002) analisou as articulações teóricas e práticas do feminismo com base em uma "política de localização", que se engendra de modo parcial, provisório e não universal. Assim, a "teoria feminista deixa de querer habitar apenas nesse espaço da 'mulher' e passa a querer entender as imbricações das várias multitudes contidas nessas mulheres" 
(OLIVEIRA, 2010, p. 30). Os efeitos do trabalho de Rich e outras teóricas implicou a afirmação da produção de saberes críticos e, ao mesmo tempo, sensíveis às múltiplas maneiras com que masculinidades e feminilidades coexistem em um mesmo tempo histórico, desenhando novas trilhas para as lutas sociais.

Nota-se, assim, que no decorrer da segunda metade do século $X X$ a composição de certos movimentos sociais, imagens e discursos que circularam em alguns países da Europa e Estados Unidos, implicou efeitos diversos nas trajetórias de homem e mulheres de países como o Brasil (PINTO, 2010). Em contrapartida, as produções de feministas que eram organizadas em locais distintos e experimentavam modos de vida não hegemônicos, como as brasileiras, chicanas e indianas, foram fundamentais na articulação do pós-feminismo (COSTA, 2009). Para elucidar tal afirmação, passamos a um breve mapeamento de algumas lutas que se desenharam no Brasil entre as décadas de 1960 e 1990.

\section{LUTAS EMPREENDIDAS NO BRASIL}

Os primeiros anos da década de 1960, no Brasil, foram marcados por uma intensa efervescência cultural e política, principalmente nas grandes cidades como São Paulo e Rio de Janeiro. Ao som da MPB (Música Popular Brasileira), emergiram conflitos entre grupos de estudantes e do próprio governo de um lado e, de outro, militares e uma classe média assustada (PINTO, 2010). O ano de 1964 inaugurou um golpe militar no país, sucedido por quase duas décadas de intensos conflitos que, principalmente após a instauração de um decreto emitido pelo regime militar no ano de 1968, conhecido como Ato Institucional n. 5 (Al-5), resultou na ampliação nos casos de processos de exílio, tortura, aprisionamento e morte de intelectuais, jornalistas, escritores e artistas, que se expressavam de diferentes formas contra a política ditatorial (DREIFUSS,1981). Para avançar no relato sobre as lutas empreendidas no Brasil, duas dimensões serão abordadas: as décadas de 1960 e 1970, com seus limites e experimentações, bem como os novos ativismos que colocaram em cena a imprensa e a produção de conhecimento acadêmico. 


\subsection{DÉCADAS DE 1960 E 1970: LIMITES E EXPERIMENTAÇÕES}

Nesse cenário de lutas, coexistiam, na segunda metade da década de 1960, um modelo de feminilidade tradicional e o anúncio de novas formas de viver entre as mulheres que, na década de 1970, expressavam-se com mais visibilidade, principalmente em consequência dos impactos do movimento feminista (BUTLER, 2003). Nessa conjuntura, as produções midiáticas (propagandas, jornais e revistas) fizeram circular imagens de feminilidade associadas a prazer e liberdade, ao mesmo tempo em que reafirmavam que esses direitos eram alcançáveis por meio do consumo de produtos industrializados (SOHN, 1991).

Outra reversão no jogo de poderes foi disseminada na mídia com a emergência de uma nova imagem de mulher, capaz de transitar de forma mais livre, flexível e autônoma por diversas esferas da sociedade, em especial a esfera profissional. Porém, mesmo que tal discurso ressaltasse algumas diferenças, em suas entrelinhas circulava a ideia de que as novas vivências das mulheres se expressavam como reflexo de um quadro de esquizofrenia, loucura e perturbação mental (SOHN, 1991), talvez como expressão de desvio em relação a uma suposta natureza feminina já naturalizada.

No final da década de 1960, portanto, diferentes composições implicaram em experimentações tanto de formas instituídas de vida, materializadas em discursos e práticas conservadoras, quanto em vivências libertárias como, por exemplo, a emergência de um ativismo feminista crítico e combatente (PINTO, 2010). O fato de mulheres terem sido exiladas durante a ditadura possibilitou o seu contato com escritos e propostas feministas que ganhavam consistência em outros países, sobretudo na Europa e Estados Unidos. Esses encontros contribuíram para a construção do movimento feminista brasileiro no final dos anos 1960s, subsidiando as pautas do movimento de mulheres no Brasil (ZIRBEL, 2007).

A exemplo de movimentos engendrados em países europeus e estadunidense, a composição do movimento feminista brasileiro ocorreu majoritariamente com a participação de mulheres brancas, de classe média e com nível superior de instrução. Organizadas inicialmente em torno de grupos de oposição à ditadura, as feministas teceram o movimento alicerçadas na problematização dos efeitos dos modelos conservadores no cotidiano das mulheres 
e sobre a necessidade de lutar por direitos femininos. Elas não só questionaram as estruturas públicas e privadas de poder, por meio de denúncias das opressões operadas nas políticas estatais, no mercado de trabalho e nas relações conjugais e familiares, como reivindicaram reformas legais e trabalhistas, a legalização do aborto e a construção de uma política governamental de coibição das práticas de violência contra as mulheres (BARSTED, 1994). Deste modo, as feministas constituíram um campo político onde as mulheres eram o foco, o que contribuiu sobremaneira para constituí-las como sujeitos de direito.

Destaca-se também o aumento de mulheres nos espaços públicos, que iam desde o mercado de trabalho até os locais de passagem como ruas, praças, bares e locais de entretenimento. Essa ocupação aconteceu em concomitância com algumas transformações sutis que se delineavam no âmbito privado. Santana (2009) destaca que, nessa conjuntura, a maternidade passou a ser pensada a partir de outros parâmetros, principalmente no que se referia à preocupação com a gravidez planejada e com a redução do número de filhos por casal, o que foi possível também devido ao maior acesso à pílula anticoncepcional. Possibilitada pela ciência e tecnologia, a anticoncepção pôde ser compreendida como mais uma ruptura em relação à passividade com que as mulheres "acolhiam" a maternidade como seu "destino". Poder decidir sobre o momento e também sobre a possibilidade de aceitar ou recusar a maternidade, representou uma conquista que colocou em evidência a autonomia na tomada de decisão em relação ao corpo e à vida.

Ao reivindicarem que as mulheres ocupassem outros espaços e práticas que se ensaiavam para além da maternidade e do casamento, as jovens brasileiras da década de 1970 elencaram como prioridade o estudo e a carreira profissional. Exemplos desses movimentos foi o aumento de mulheres no ensino universitário, bem como o ingresso das brasileiras em carreiras tidas como propriedade exclusivamente masculina, como medicina, arquitetura, engenharia e direito (BRUSCHINI e LOMBARDI, 1999). Desse modo, no contexto autoritário que se configurava nesse período no Brasil, "a questão feminista ganharia lentamente espaço de visibilidade, tanto pelas reivindicações mais gerais, como pela introdução de uma agenda que discutia problemáticas de cunho mais subjetivo e das relações interpessoais" (SANTANA, 2009, p.5). 
Ainda que o ativismo feminista tenha demonstrado sua capacidade de articulação política, as mulheres sofreram críticas de grande parte dos movimentos de resistência à ditadura, pois muitos consideravam que, na luta contra o autoritarismo, a questão das mulheres parecia irrelevante e, até mesmo, reacionária. As avaliações pejorativas às propostas feministas resultaram em dificuldades na consolidação e visibilidade do movimento; apenas após 1975, o feminismo conquistou ampla visibilidade na conjuntura brasileira, principalmente em virtude de a ONU ter declarado este como o ano Internacional da Mulher (BARSTED, 1994).

A partir desse momento, as feministas ganharam maior evidência na imprensa brasileira, sendo as questões relacionadas aos direitos das mulheres debatidas em diferentes aparatos midiáticos, como, por exemplo, os jornais "Nós Mulheres" e o "Brasil-Mulher", que se mantiveram ativos até 1980 (CARDOSO, 2004). O engajamento social e político das revistas e jornais feministas resultaram no posicionamento destes materiais ao lado dos cerca de 150 jornais considerados "alternativos" na década de 1970. Entre 1974 e 1980, a imprensa feminista abordava temas gerais, como as desigualdades sociais e os movimentos sociais que tinham relevância naquele momento, bem como temáticas ligadas à anistia e denúncias das práticas de repressão associadas ao regime militar (DREIFUSS, 1981).

Ações, discursos e movimentos feministas eram disseminados em centros de estudos e pesquisas, Organizações Não-Governamentais (ONGs), encontros nacionais e internacionais e por uma imprensa feminista forte e crítica (BARSTED, 1994). As redes feministas contavam, ainda, com o apoio financeiro de agências internacionais, o que permitiu independência financeira do governo brasileiro no desenvolvimento de projetos e eventos acadêmicos, entre outras estratégias de reivindicação e divulgação.

Algumas dessas ações se organizaram em movimentos populares que foram fortemente protagonizados pelas Comunidades Eclesiais de Base (CEBs) da Igreja Católica, atuantes em bairros pobres e favelas em prol da educação, saneamento, habitação e saúde (FREIRE, 1981). Tais interlocuções foram importantes para que o movimento feminista estabelecesse uma interface de luta em favor das necessidades sociais e das reivindicações das mulheres de classes populares, 
possibilitando a disseminação de novas percepções sobre os modos heterogêneos como as mulheres viviam no Brasil, assim como será problematizado a seguir.

\subsection{NOVOS ATIVISMOS}

Na década de 1980, o movimento feminista ajudou a tecer discursos e práticas que contribuíram para o restabelecimento democrático no Brasil. Como consequência disso, ressalta-se a participação direta de feministas na reorganização de partidos políticos e propostas de governo após o período de ditadura no país. Essa inserção garantiu que questões relativas às condições das mulheres estivessem em pauta nas políticas governamentais, por meio tanto da ascensão de ativistas em cargos políticos, como da realização de debates sobre questões relacionadas à violência, às diferentes expressões da sexualidade e do racismo, sobre o direito ao trabalho, à terra, à saúde, à igualdade no casamento e ao aborto. Exemplo dos efeitos dessas conquistas pode ser verificado em um debate realizado pela Folha de São Paulo em 1993 entre cinco feministas atuantes na formulação de políticas de saúde voltadas à mulher, em especial na luta pela descriminalização e legalização do aborto.

Longe de ser resolvida, a questão do aborto no Brasil pode ser compreendida como um campo de lutas tensionado, complexo e difícil de ser abordado em razão do conservadorismo religioso presente em nosso país. De qualquer maneira, as discussões que emergiram nesse período, ora de maneira marginal iniciada em grupos localizados, ora impulsionada pela iniciativa da mídia mais ampla, evidenciam posições distintas de homens e mulheres, bem como das instituições sociais, sobre uma questão polêmica que atravessa a vida da população de maneira significativa.

Após o período do regime militar, o Brasil viveu a crise do petróleo, além de acumular uma enorme dívida externa e interna, o que demarcou um período de recessão da economia e dificuldades na reorganização da política partidária. Essa conjuntura possibilitou uma atuação ainda mais forte de feministas com suas pautas de reivindicação nos sindicatos, organismos governamentais e na elaboração de políticas públicas. Barbosa e Lage (2015), assim como Pinto (2010), destacam que, entre as conquistas do feminismo brasileiro, a criação do Conselho Nacional da 
Condição da Mulher (CNDM) foi fundamental, sendo que, uma parceria consolidada em 1984 com o Centro Feminista de Estudos e Assessoria (CFEMEA), resultou no desenvolvimento de uma campanha nacional para a inclusão dos direitos das mulheres na nova Carta Constitucional. O resultado dessas articulações refletiu na implementação de direitos femininos no texto da Constituição promulgada em 1988, o que assinalou novamente uma ruptura com a homogeneidade até então vigente.

A importância política da luta feminista no processo de redemocratização do Brasil também possibilitou a institucionalização de diversos órgãos públicos, programas governamentais e iniciativas focados na problematização das condições das mulheres brasileiras, como, por exemplo, a criação, em 1983, do Programa de Assistência Integral à Saúde da Mulher e dos Conselhos Estaduais e Municipais dos Direitos da Mulher, e a fundação, em 1985, do Conselho Nacional dos Direitos da Mulher, das Delegacias de Atendimento às mulheres vítimas de violência, dos Abrigos e dos Centros de Orientação Jurídica à mulher vítima de violência (BARSTED, 1994).

Nas duas últimas décadas do século $\mathrm{XX}$, a imprensa feminista brasileira assumiu um novo tom, focalizando as pautas específicas do movimento, como questões relacionadas à saúde da mulher, ao trabalho feminino, à violência contra as mulheres, às expressões da sexualidade e a questões legais, bem como notícias sobre o próprio feminismo (CARDOSO, 2004). Nesse período, as questões políticas no Brasil circulavam em torno do processo de abertura democrática, da reforma de leis trabalhistas e cíveis e da importância da participação das mulheres nas instâncias estatais. Ressalta-se que a reivindicação principal era a igualdade entre homens e mulheres a partir das diferenças que os atravessam.

Em 1992, surgiram no país a "Revista de Estudos Feministas" e os "Cadernos PAGU", periódicos de circulação internacional que buscaram promover debates acadêmicos no campo dos estudos feministas e de gênero. Ainda na década de 1990, surgiram as revistas "Gênero", publicada por pesquisadoras da Universidade Federal Fluminense, e o "Espaço Feminino", publicado pelo Núcleo de Estudos de Gênero e pesquisa sobre a Mulher da Universidade Federal de Uberlândia (GROSSI, 2004). Tais conquistas anunciaram a seriedade e a força com que as lutas feministas se mesclaram a práticas, discursos, imagens e instituições brasileiras.

R. Inter. Interdisc. INTERthesis, Florianópolis, v.13, n.2, p. 141-164 Mai-Ago. 2016 
Outros campos de debate foram os encontros brasileiros e latino-americanos de ativistas, que se consolidaram como espaços de análise e interlocução sobre contextos, discursos e práticas que implicavam na subalternização de mulheres do terceiro mundo e na articulação de regimes políticos de dominação do corpo feminino. Nos referidos encontros, aconteciam debates críticos sobre as dimensões da sexualidade, do prazer, sobre os tabus construídos em torno da contracepção e do aborto, bem como sobre a luta pela igualdade de direitos. Adrião, Toneli e Maluf (2011, p. 662) mostram que esses eventos se estruturaram como "lugares de exercício de um modo de ser feminista e de fazer feminismo", que se atualizaram no caminho do trabalho "em rede" entre ativistas nacionais e internacionais.

Em paralelo a esses eventos, Grossi (2004, p.213) ressalta que as feministas também se ocuparam em analisar, de modo crítico, os elementos que institucionalizavam uma perspectiva hegemônica de "ser brasileira(o)" e os impactos disso no cotidiano da população. Tais problematizações resultaram na abertura de linhas de pesquisa em programas de pós-graduação que refletiram sobre as intersecções das construções de gênero relacionadas a elementos culturais, sociais e políticos.

Pode-se dizer que parte dessas produções sociais relativas às lutas feministas empreendidas no Brasil repercutiu em outros países, contribuindo para problematizar os múltiplos modos de vida articulados ao debate sobre gênero. Esses modos de vida, resgatando Foucault mencionado no início deste estudo, foram da sujeição às práticas de libertação (FOUCAULT, 2011) sendo que ambos mantiveram-se indissociáveis neste mapeamento. Ainda mais em se tratando da análise de um país como o Brasil, marcado pela amplitude territorial e pela pluralidade cultural, social e política. De todo modo, pode-se dizer que as lutas políticas empreendidas na segunda metade do século $\mathrm{XX}$, marcadas por produções teóricas e práticas situadas, contribuíram para a construção de perspectivas pósfeministas que afirmaram a multiplicidade. 


\section{CONSIDERAÇÕES FINAIS}

Como pudemos demonstrar ao longo deste ensaio, a segunda metade do século $X X$ foi marcada por embates e alianças entre forças heterogêneas que ora reproduziam práticas conservadoras de gênero, ora se configuravam como pontos de resistência, implicando múltiplos efeitos na vida da população. Materializadas em discursos, enunciados, imagens e movimentos sociais, as tensões presentes nesse período produziram avanços e retrocessos no campo dos direitos de cidadania. Tais movimentos ganharam diferentes contornos sociais que puderam ser explorados tanto na primeira parte do artigo, que examinou os movimentos europeus e norte americanos, quanto na segunda parte, que se debruçou na análise da realidade brasileira. A singularidade que atravessou cada um desses espaços pode ser descrita e sintetizada. Na Europa e nos Estados Unidos, países fortalecidos econômica e institucionalmente à época analisada, os enfrentamentos ocorreram em meio a discussões dos mais variados tipos, tendo na academia, na arte e na imprensa jornalística seus maiores aliados. Já no caso do Brasil, ficou notável sua herança colonialista e sua dependência de reconhecimento das ditas sociedades desenvolvidas. Mesmo diante desse limitador, porém, as lutas em nosso país tiveram repercussão que superaram suas fronteiras, inspirando a problematização sobre os direitos em países vizinhos.

De todo modo, consideramos relevante sublinhar quatro pontos nesta finalização. Primeiramente, consideramos que as lutas empreendidas na segunda metade do século XX ocorreram em meio a focos de poder e de resistência, que se delineavam, articulavam e se enfrentavam diferentemente a cada novo obstáculo emergente. Diante desse emaranhado de forças díspares, pudemos percorrer algumas práticas mais conservadoras bem como focos de resistência pulverizados em meio aos avanços tecnológicos do pós-guerra; imagens e discursos veiculados nos meios de comunicação de massa; maior participação das mulheres na formação acadêmica e acesso mais facilitado ao mercado de trabalho, com seus impactos nas relações familiares; afirmação de direitos femininos no campo legal e na elaboração de políticas públicas; e, principalmente, movimentos organizados de mulheres ativistas, ligadas ou não às academias. Tais iniciativas resultaram em fissuras nos processos de construção de perspectivas tradicionais de gênero e possibilitaram a 
visibilidade, mas também a produção, de diferentes expressões tanto de feminilidades quanto de masculinidades.

Em segundo lugar, cabe destacar que ao tomarmos como objeto de análise o referido período, encontramos uma série de situações que evidenciaram a potência para rupturas e transformações de seus agentes. Longe de consolidarem-se como um campo apaziguado, tais lutas deram visibilidade às dimensões combatente e mutante da existência. A análise dessas lutas, porém, requer uma abertura ao imponderável que elas colocam em curso. Nessas lutas, os agentes alternam a tomada da palavra e do poder a todo o momento, sem se fixar em posições consolidadas de vítima ou opressor. Na variação contínua, as distribuições de poder e as intervenções do saber foram analisadas em sua potência de efetuação que é localizada e singular, dificultando formas de controle perenes e generalizações rasas.

Pode-se dizer, em terceiro lugar, que a rede institucional que construímos e legitimamos historicamente para organizar a vida em sociedade aciona práticas que atingem desde as grandes estruturas institucionais até a vida privada do sujeito comum que as coloca em funcionamento, de maneira singular, em seu cotidiano. Cada uma dessas instâncias participa da produção dos dispositivos de poder que incidem sobre as diversas dimensões da existência, incluindo aí a questão dos gêneros. Cabe dizer que esse duplo condicionamento não envolve a mera duplicação do geral no local ou vise-versa. Ambos funcionam por articulações recíprocas, inscrevendo-se um no outro.

Por fim, cabe considerar que ao analisar as lutas políticas empreendidas nesse período, ou em qualquer outro, corremos o risco de cair em uma armadilha muito comum: a de condenar as mulheres ao lugar de vítimas e os homens ao de opressores, paralisando, assim, a análise de lutas que são vivas, complexas e vão além dessas polaridades simplificadoras. Na perspectiva foucaultiana, os pontos de resistência acontecem em meio a condições adversas de existências, abalando-as à medida que as diferenças ganham contornos, expressões e intensidades variadas. Nas lutas engendradas em países da Europa, na América do Norte e no Brasil, coexistiram linhas que se intercruzaram, compuseram e romperam, dando contornos inusitados às maneiras de viver que foram povoadas por diferenças, combates e divergências. Assim, constatamos nessas lutas o argumento foucaultiano que 
sublinha a importância das análises parciais e localizadas, sensíveis às práticas globais e às iniciativas situadas e micropolíticas que insistem na exploração e rompimento das fronteiras e nas brechas da história. Daí a importância da análise detalhada dos enunciados, dos efeitos das imagens e da participação díspar de múltiplos agentes.

R. Inter. Interdisc. INTERthesis, Florianópolis, v.13, n.2, p. 141-164 Mai-Ago. 2016 


\title{
WOMEN AND POLITICAL STRUGGLES: ACHIEVEMENTS AND LIMITATIONS LIVED IN THE SECOND HALF OF TWENTIETH CENTURY
}

\begin{abstract}
:
The second half of the twentieth century was a period marked by important achievements and setbacks in the struggle for women's rights field. This study mapped out and described part of speeches, images and movements undertaken in that historical period and its effects on people's lives. Adopting a perspective of historical and theoretical analysis, the description looked up, first, the struggles carried out in some countries of Europe and the United States, highlighting its main challenges and difficulties. Then, the struggles undertaken are mapped in Brazil, with the analysis axis facing women inequality. Finally, it is considered that the political struggles carried out in the analyzed period had as greatest merits the disruption and exploitation of gender boundaries.
\end{abstract}

Keywords: Women. Politics. Resistance.

\section{MUJERES Y LUCHAS POLÍTICAS: LOGROS Y LIMITACIONES EN LA SEGUNDA MITAD DEL SIGLO XX}

\section{Resumen}

La segunda mitad del siglo XX fue un período marcado por logros importantes en el campo de los derechos de las mujeres. El presente estudio mapeó y describió parte de los discursos, imágenes y movimientos realizados en ese período histórico, así como sus efectos en la vida de la población. Adoptando una perspectiva de análisis teórico e histórico, la descripción se dedicó, en primer lugar, acerca de las luchas emprendidas en algunos países de Europa y los Estados Unidos, destacando sus desafíos y dificultades. Luego, se mapearon las luchas emprendidas en Brasil, teniendo como eje de análisis el enfrentamiento de las desigualdades. Al final, se considera que las luchas políticas realizadas en el período analizado tuvieron como mayor mérito la ruptura y la exploración de los límites del género.

Palabras clave: Mujeres. Política. Resistencia. 


\section{REFERÊNCIAS}

ADRIÃO, K. G.; TONELI, M. J; MALUF, S. O movimento feminista brasileiro na virada do século XX: reflexões sobre sujeitos políticos na interface com as noções de democracia e autonomia. Revista de Estudos Feministas, n. 3, p. 662-682, 2011.

BARBOSA, G. S.; LAGE, A. C. Reflexões sobre o movimento feminista na América Latina. Revista Lugares de Educação, v. 5, n. 11, p. 92-103, 2015.

BARSTED, L. Em busca do tempo perdido: mulher e políticas públicas no Brasil 1983-1993. Revista de Estudos Feministas, v.2, p. 38-54, 1994.

BRUSCHINI, C.; LOMBARDI, M. R. Médicas, arquitetas, advogadas e engenheiras: mulheres em carreiras de prestígio. Revista Estudos Feministas, v. 7, p. 9-24, 1999.

BUTLER, J. Fundamentos Contingentes: o feminismo e a questão do "pósmodernismo". Cadernos PAGU, v.11, p.11-42, 1998.

. Corpos que pesam: sobre os limites discursivos do "sexo". In: GUACIRA Lopes Louro (Org.). O corpo educado: pedagogias da sexualidade. Belo Horizonte: Autêntica, 2001, p.153-172.

Problemas de gênero: feminismo e subversão da identidade. Rio de Janeiro: Civilização Brasileira, 2003.

CARDOSO, E. Imprensa feminista brasileira pós 1974. Revista Estudos Feministas, v. 12, p. 37-55, 2004.

CARILLO, J. Entrevista com Beatriz Preciado. Revista Poiésis, n. 15, p. 47-71, 2010.

CARVALHAES, F. F. Mulheres no crime, deslizamentos de fronteiras. 2015. 158 f. Tese (Doutorado) - Universidade Federal de Santa Catarina, Florianópolis, 2015.

COSTA, C. L. A urgência do pós-colonial e os desafios dos feminismos latinoamericanos. Terceira Margem, Rio de Janeiro, Número 20, pp. 70-85, 2009. 
DREIFUSS, R. A. 1964: A Conquista do Estado. Petrópolis: Vozes, 1981.

ERGAS, Y. O sujeito mulher. O feminismo dos anos 1960-1980. In: DUBY, Gorges e PERROT, Michelle (Orgs.). História das mulheres no Ocidente: o século XX. Porto: Afrontamento, 1991. p. 581-611.

ESPECIALISTAS discutem legalização do aborto. Folha de São Paulo. São Paulo, 1993. Disponível em http://acervo.folha.com.br/fsp/1993/10/31/264/. Acesso em: $15 / 02 / 2014$.

FERNANDES, M. C. V.; VASCONCELOS, M. B. F. A história de mulheres no campo da matemática. In: Encontro Paraibano de Educação Matemática - EPBEM. Anais... 2010. p. 48-59.

FOUCAULT, M. História da sexualidade I: A vontade de saber. Rio de Janeiro: Graal, 1988.

2000.

A arqueologia do saber. Rio de Janeiro: Forense Universitária,

. Ditos \& Escritos V: Ética, Sexualidade, Política. Rio de Janeiro: Forense Universitária, Brasil, 2011.

FREIRE, P. Pedagogia do Oprimido. Rio de Janeiro: Paz e Terra, 1981.

DUBY, G.; PERROT, G. História das mulheres no ocidente: o século XX. Porto: Afrontamento, 1991. v. 5, p. 185-219.

GROSSI, M. A Revista Estudos Feministas faz 10 anos - Uma breve história do feminismo no Brasil. Revista Estudos Feministas, v. 12, p. 211-222, 2004.

HARAWAY, D. Saberes localizados: a questão da ciência para o feminismo e privilégio da perspectiva parcial. Cadernos PAGU, n. 5, p. 7-41, 1995.

LAGRAVE, R. M. Uma emancipação sobre tutela. In: DUBY, Gorges e PERROT, Michelle (Orgs.). História das mulheres no Ocidente: o século XX. Porto: Afrontamento, 1991, p. 505-542. 
LEFAUCHEUR, N. Maternidade, Família, Estado. In: DUBY, G.; PERROT, M. (Orgs.). História das mulheres no Ocidente: o século XX. Porto: Afrontamento, 1991, p. 479-503.

MARINI, M. O lugar das mulheres na produção cultural: o exemplo da França. In: DUBY, G.; PERROT, M. (Orgs.). História das mulheres no Ocidente: o século XX. Porto: Afrontamento, 1991. p. 351-377.

OLIVEIRA, J. M. Os feminismos habitam espaços hifienizados - a localização e interseccionalidade dos saberes feministas. Revista Ex Aequo, n. 22, p. 25-39, 2010.

PASSERINI, L. Mulheres, consumo e cultura de massas. In: DUBY, Gorges e PERROT, Michelle (Orgs.). História das mulheres no Ocidente: o século XX. Porto: Afrontamento, 1991, p. 381-400.

PINTO, C. R. J. Feminismo, História e poder. Revista de Sociologia e Política, v. 18, p. 15-23, 2010.

PISCITELLI, A. Re-criando a (categoria) mulher?. In: ALGRANTI, L. M. (Org.). A prática feminista e o conceito de gênero. Campinas: Editora IFCH/Unicamp, 2002, p. 7-42.

PRECIADO, B. Multidões queer: notas para uma política dos "anormais". Revista de Estudos Feministas, v. 19, n. 1, p. 11-20, 2011.

$\mathrm{RICH}$, A. Notas para uma política de localização. In: MACEDO, A. G. M. (Org.). Gênero, desejo e identidade. Lisboa: Cotovia, 2002. p. 15-35.

SANTANA, M. C. B. Discursos, desejos e tramas: as reinvenções amorosas e afetivas das mulheres de Teresina na década de 1970. In: Anais de Resumos: Simpósio Nacional de História - História e Ética, Fortaleza: ANPUH, 2009.

SINEAU, M. Direito e Democracia. In: DUBY, G.; PERROT, M. (Orgs.). História das mulheres no Ocidente: o século XX. Porto: Editora Afrontamento, 1991, p. 551581.

SOHN, A. M. Entre duas guerras. In: DUBY, G.; PERROT, G. História das mulheres no Ocidente: o século XX. Porto: Afrontamento, 1991. v. 5, p. 115-145. 
THÉBAUD, Fr. Introdução. In: DUBY, G.; PERROT, M. (Orgs.). História das mulheres no Ocidente: o século XX. Porto: Afrontamento, 1991.p. 9-23.

ZIRBEL, I. Estudos Feministas e Estudos de Gênero no Brasil: Um Debate. 2007. 212 f. Dissertação (Mestrado em Sociologia Política) - Universidade Federal de Santa Catarina, Florianópolis, 2007.

Artigo

Recebido em 04 de Novembro de 2015

Aceito em 31 de Maio de 2016

R. Inter. Interdisc. INTERthesis, Florianópolis, v.13, n.2, p. 141-164 Mai-Ago. 2016 